\title{
Prevalence and risk factors of pre-hypertension in Congolese pre and post menopausal women.
}

\author{
Muchanga MJS ${ }^{1,2}$, Lepira $\mathrm{FB}^{3}$, Tozin $\mathrm{R}^{1}$, Mbelambela EP², Ngatu $\mathrm{NR}^{4}$, Sumaili EK ${ }^{3}$, Makulo JR ${ }^{3}$, Suganuma $\mathrm{N}^{2}$
}

1. Department of Obstetrics and Gynecology, Kinshasa University Hospital, Kinshasa, Democratic Republic of the Congo.

2. Department of Environmental Medicine, Kochi Medical School, Kochi University, Kochi, Japan.

3. Department of Internal Medicine, Kinshasa University Hospital, Kinshasa, Democratic Republic of the Congo.

4. Graduate School of Health and Nursing Sciences, University of Kochi, Kochi, Japan.

\begin{abstract}
Objectives: We aimed to assess the prevalence of prehypertension and its associated factors in a population of Congolese pre and postmenopausal women.

Methods: We had consecutively recruited 200 women (100 premenopausal and 100 postmenopausal) aged 40 - 60 years at the department of Gynecology and Obstetrics, University of Kinshasa Hospital, and AKRAM Medical Center in Kinshasa, DRC. An interview was carried out using a questionnaire that comprised questions related to lifestyle, menses characteristics, medical history of diabetes, CVD, hypertension, current antihypertensive medication and use of traditional medicine. In addition, physical examination and biological measurements were performed. Multivariate logistic regression analysis was used to assess associated factors with prehypertension.

Results: Of the participants, 34\% were normotensive, $38.5 \%$ prehypertensive and $27.5 \%$ hypertensive. Compared to normal blood pressure, prehypertension was common in the older (age $>50$ years of age) women. Menopause, the use of traditional medicine and older age were associated with prehypertension. However, only menopause (aOR: 2.71; 95\%CI: 1.10-3.52) and the use of traditional medicine (aOR: 2.24; 95\% CI: 1.07-4.7) remained associated with prehypertension in a multivariate logistic regression analysis.
\end{abstract}

Conclusion: This study showed that prehypertension is common among Congolese menopausal women, and that menopause and the use of traditional medicine were the main factors associated with prehypertension.

Keywords: Pre-hypertension, Congolese pre and post menopausal women.

DOI: http://dx.doi.org/10.4314/ahs.v16i4.14

Cite as: Muchanga MJS, Lepira FB, Tozin R, Mbelambela EP, Ngatu NR, Sumaili EK, Makulo JR, Suganuma N. Prevalence and risk factors of pre-hypertension in Congolese pre and post-menopausal women. Afri Health Sci 2016;16(4): 979-985. http://dx.doi.org/10.4314/ahs. v16i4.14

\section{Introduction}

According to the seventh report of the Joint National Committee on Prevention, Detection, Evaluation and Treatment of High Blood Pressure (JNC7), "Prehypertension" is defined as a systolic blood pressure (SBP) of 120-139 $\mathrm{mmHg}$ and/or diastolic blood pressure (DBP) of $80-89 \mathrm{mmHg}$ in adults aged 18 years or more ${ }^{1}$. Individuals with pre-hypertension are at high risk of developing clinical hypertension compared to people with lower

\section{Corresponding author:}

Muchanga MJS,

Department of Obstetrics and Gynecology, Kinshasa University Hospital, Kinshasa, Democratic Republic of the Congo.

Email: muchanga_sifa@yahoo.fr

African Health Sciences Vol 16 Issue 4, December, 2016 blood pressure (BP) levels. It is related to the morbidity and mortality of cardiovascular disease $(C V D)^{1,2}$. Identification of individuals with pre-hypertension is an important strategy to prevent the progression to hypertension and, thus, reducing the risk of CVD in the general population $^{3}$.

Unlike men, women show an abrupt increase in BP around the fifth decade of life, and by sixth decade, surpass men in the incidence of primary hypertension ${ }^{4}$. Researchers have not been able to separate the effects of sex hormones from the effect of aging on arterial pressure, mainly because sex steroid concentrations decrease in humans as they age $\mathrm{a}^{3,5}$.

It has been reported that the prevalence of pre-hypertension in women is higher than in their male counterparts, and they present increased rates of cardiovascular 
disease with advancing age ${ }^{3}$. Menopausal and perimenopausal periods are critical periods for emergence of CVD because of change in hormonal pattern ${ }^{6}$. Women tend to pass most of the part of their life in the menopausal period and it is estimated that in 2030, 1.2 billion of women will be peri- or postmenopausal, and that this total will increase by 4.7 million a year. Although overall number will have increased by 2030 , the proportion of postmenopausal women living in the industrialized regions will have declined to $24 \%$, and $76 \%$ will be living in developing countries ${ }^{7}$. Because of these predicted changes in population structure, physicians are beginning to consider menopause not only as a natural phenomenon but also as a major public health problem ${ }^{7}$. Apart from changes in hormonal pattern, environmental factors such as exposure to heavy metals and/or non secured herbal medicines could contribute to this increased prevalence of Pre-hypertension mainly in the developing World ${ }^{8}$.

Hypertension is a major risk factor for cardiovascular disease (CVD) in the sub-Saharan African region, as in developed countries and there are several reports on the high prevalence of hypertension in some African cities ${ }^{9-12}$. Studies related to the relationship between menopausal status and cardiovascular risks, such as pre-hypertension, metabolic syndrome, chronic kidney failure are scarce ${ }^{13-17}$. On the other hand, most studies related to pre-hypertension were conducted in other population than menopausal women, such as adolescents ${ }^{18}$ and the general popula$\operatorname{tion}^{19-23}$. To the best of our best knowledge, there have been no reported studies on pre-hypertension and its relationship with menopausal status neither in the Democratic Republic of the Congo (DRC), nor in any other sub-Saharan African country.

Given the public health burden of menopause, we aimed to assess the rate of pre-hypertension and associated factors in a population of Congolese post-menopausal and pre-menopausal women.

\section{Methods}

\section{Participants and study design}

A cross-sectional study was conducted from January through June 2010 at the Department of Gynecology and Obstetrics, University of Kinshasa Hospital, and AKRAM Medical Center in Kinshasa, DRC. A total of 200 women aged 40 - 60 years participated in the study.
A convenience sampling procedure by consecutive and stratified recruitment was used to select subjects. Details of the methods were published in our previous report ${ }^{17}$. Briefly, an interview was conducted; information regarding lifestyle (self-reported physical activity, alcohol consumption and smoking habit), menses characteristics, duration of menopause, family and past medical history of diabetes, CVD, hypertension, current antihypertensive medication and use of traditional medicine was collected. A physical examination was performed; adiposity was estimated with the use of body mass index (BMI) and waist circumference (WC). Seated blood pressure (BP) was measured on the left arm from each subject with the use of Omron M1 digital electronic blood pressure/pulse monitor (OMRON Corporation, Tokyo) after five minutes of relaxation; average of $3 \mathrm{BP}$ measurements were used for analysis. Combur test was used to assess dipstick proteinuria. Biological measurements were performed after $12 \mathrm{~h}$ fasting (total cholesterol, high density lipoprotein, cholesterol, triglycerides, and glucose; low density lipoprotein was calculated.

\section{Definition of Pre-hypertension and menopause}

Pre-hypertension was defined according to $\mathrm{JNC7}^{1}$. BP measurements and self-reported high BP or hypertension, use of antihypertensive drugs at baseline were used to classify subjects as having normal BP, pre-hypertension, or hypertension. Normal BP was defined as $\mathrm{SBP}<$ $120 \mathrm{~mm} \mathrm{Hg}$ and DBP $<80 \mathrm{~mm} \mathrm{Hg}$. Pre-hypertension was defined as SBP 120 to $139 \mathrm{~mm} \mathrm{Hg}$ and/or DBP 80 to 89 $\mathrm{mm} \mathrm{Hg}$. Hypertension was defined as SBP $\geq 140 \mathrm{~mm} \mathrm{Hg}$ and/or DBP $\geq 90 \mathrm{~mm} \mathrm{Hg}$ or by the use of antihypertensive medications.

Women were defined as post-menopausal if they reported their last menses to be at least 12 months prior to this study, and pre-menopausal if they had had an unchanged or irregular menstrual pattern ${ }^{24}$.

\section{Ethical consideration}

Each participant provided a written informed consent and the study was approved by the Research Ethics committee of the faculty of Medicine, University of Kinshasa.

\section{Statistical analysis}

Data was expressed as relative frequency using percentages. Chi square was performed to compare normally distributed categorical variables. Multivariate logistic re- 
gression analysis was performed to evaluate the relative contribution of menopause to the risk of pre-hypertension after adjusting for other covariates (age, and education level, BMI, smoking, alcohol intake, duration of menopause).

As it is known that menopause is related to age, we first check if there is interaction between the two variables. The interaction term was not significant, then we put both of them in the regression model; $\mathrm{P}$ value $<0.05$ defined the statistical significance. All statistical analyses were performed with STATA SE, 10.1(Statacorp, TX, USA).

\section{Results}

Of the 200 pre and post-menopausal women who participated in this study, 34\% were normotensive, 38.5\% were pre-hypertensive and the remaining $27.5 \%$ were hypertensive. Compared to normal blood pressure, pre-hypertension was more common in the older age group (age $>50$ years; $\mathrm{p}=0.03$ ).

According to the menses status, when we divide the study group in to pre and post-menopausalwomen; post-menopausal women were more likely to be pre-hypertensive $(p=0.03)$ and inversely, pre-menopausal women were normotensive $(\mathrm{p}=0.04)$ (table1)

Table 1. Baseline socio-demographic characteristics of the study population according to BP characterization.

\begin{tabular}{clll}
\hline Characteristic & $\begin{array}{l}\text { Normal BP } \\
(\mathbf{n}=\mathbf{6 8})\end{array}$ & $\begin{array}{c}\text { Pre-hypertension } \\
(\mathbf{n}=\mathbf{7 7})\end{array}$ & $\begin{array}{l}\text { Hypertension } \\
(\mathbf{n}=\mathbf{5 5})\end{array}$ \\
\hline Age, yrs & & & \\
$<50$ & $49(72.06)$ & $34(44.16)$ & $26(47.27)$ \\
$\geq 50$ & $19(27.94)$ & $43(55.84)^{*}$ & $29(45.50)$ \\
Menopausal status & & & \\
Pre-menopause & $46(67.65)$ & $29(37.66)^{*}$ & $25(45.45)$ \\
Post-menopause & $22(32.35)$ & $48(62.34) *$ & $30(54.55)$ \\
Married,\% & $62(91.18)$ & $67(87.01)$ & $48(87.27)$ \\
Education,\% & $51(75)$ & $61(79.22)$ & $43(78.18)$ \\
\hline
\end{tabular}

Abbreviations: BP, blood pressure, yrs, years, \%, percent.

*, $P<0.05$ comparing pre-hypertension and normal BP; Data are expressed as relative frequency in percent.

In contrast, no statistically significant differences were found between the above mentioned groups of women when considering others cardiovascular risk factors such as smoking, alcohol intake, family history of diabetes, shown in Tables 2 and 3.

Table 2. Associated clinical cardiovascular risk factors according to BP characterization.

\begin{tabular}{lccc}
\hline \multicolumn{1}{c}{ Characteristic } & $\begin{array}{c}\text { Normal BP } \\
(\mathrm{n}=68)\end{array}$ & $\begin{array}{c}\text { Pre-hypertension } \\
(\mathrm{n}=77)\end{array}$ & $\begin{array}{c}\text { Hypertension } \\
(\mathrm{n}=55)\end{array}$ \\
\hline FH-DM, \% & $10(14.71)$ & $18(23.38)$ & $14(25.45)$ \\
FH-HT, \% & $24(35.29)$ & $37(48.05)$ & $33(60)$ \\
FH-CVD,\% & - & $1(1.3)$ & $3(5.45)$ \\
Alcohol intake,\% & $14(20.59)$ & $16(20.78)$ & $8(14.55)$ \\
Smoking,\% & $1(1.47)$ & - & - \\
Use of traditional & $20(29.41)$ & $12(15.58)$ & $16(29.09)$ \\
medicine,\% & $14(20.59)$ & $10(12.99)$ & $12(21.82)$ \\
Phys. activity, \% & & & \\
BMI & $41(60.29)$ & $31(40.26)$ & $17(31.48)$ \\
Normal & $20(29.41)$ & $27(35.06)$ & $18(33.33)$ \\
Overweight & $7(10.29)$ & $19(24.68)$ & $20(36)$ \\
Obese & $26(38.24)$ & $42(54.55)$ & $30(54.55)$
\end{tabular}

Abbreviations: BP, blood pressure, BMI, body mass index, FH-CVD, family history of cardiovascular disease, FHDM, family history of diabetes mellitus, FH-HT, family history of hypertension, yrs, years, \%, percent, Phys, physical. 
Table 3. Associated biological cardiovascular risk factors according to BP characterization.

\begin{tabular}{lccc}
\hline \multicolumn{1}{c}{ Characteristic } & $\begin{array}{l}\text { Normal BP } \\
(\mathrm{n}=68)\end{array}$ & $\begin{array}{c}\text { Pre-hypertension } \\
(\mathrm{n}=77)\end{array}$ & $\begin{array}{l}\text { Hypertension } \\
(\mathrm{n}=55)\end{array}$ \\
\hline $\mathrm{TC}>200 \mathrm{mg} / \mathrm{dl}$ & $31(45.59)$ & $43(55.84)$ & $33(60)$ \\
$\mathrm{LDL}-\mathrm{c} \geq 130 \mathrm{mg} / \mathrm{dl}$ & $55(81)$ & $65(84)$ & $48(87)$ \\
$\mathrm{HDL}-\mathrm{c}<50 \mathrm{mg} / \mathrm{dl}$ & $19(27.94)$ & $21(27.27)$ & $11(20)$ \\
$\mathrm{TG} \geq 150 \mathrm{mg} / \mathrm{dl}$ & $8(11.76)$ & $18(23.38)$ & $9(16.36)$ \\
Proteinuria, \% & $24(35.29)$ & $36(48)$ & $21(38.89)$ \\
Glucose $\geq 126 \mathrm{mg} / \mathrm{dl}$ & $5(7.35)$ & $8(10.39)$ & $6(9.5)$
\end{tabular}

Abbreviations: BP, blood pressure; HDL-c, high-density lipoprotein-cholesterol; LDL-c, low-density lipoprotein-

cholesterol; TC, total cholesterol; TG, triglycerides; \%, percent.

In addition, the proportion of obese women was relatively higher among pre-hypertensive women as compared with normotensive ones; however, the level of significance of the difference was borderline $(\mathrm{p}=0.05)$ (Table 2). Furthermore, before adjustment, menopause, use of traditional medicine and older age (age $>50$ years) were associated with pre-hypertension. However, after adjustment in a multivariate logistic regression analysis, only menopause (aOR: 2.71 ; 95\%CI: 1.10-3.52) and use of the traditional medicine (aOR: 2.24; 95\% CI: 1.07-4.7) were found to be associated with hypertension. (Table 4).

Table 4. Risk factors associated with pre-hypertension:

Multivariate logistic regression analysis.

\begin{tabular}{lllll}
\hline Prehypertension & OR & $\mathbf{9 5 \% C I}$ & aOR & 95\%CI \\
\hline $\begin{array}{l}\text { Menopause } \\
\begin{array}{l}\text { Use of traditional } \\
\text { medicine }\end{array}\end{array}$ & 2.25 & $1.25-4.05$ & $\mathbf{2 . 7 1}$ & $\mathbf{1 . 1 0 - 3 . 5 2}$ \\
Age $>50$ years & 1.24 & $1.08-4.65$ & $\mathbf{2 . 2 4}$ & $\mathbf{1 . 0 7 - 4 . 7}$ \\
\hline
\end{tabular}

Logistic regression variables: menopause, use of traditional medicine, age $>50$ years, LDL-c $\geq 130 \mathrm{mg} / \mathrm{dl}$, family

history of DM, Family history of HT, education (> 12 years), alcohol intake, smoking, married, proteinuria, family

history of CVD, BMI, physical activity, waist $>88 \mathrm{~cm}$, TC $>200 \mathrm{~m} / \mathrm{dl}, \mathrm{HDL}<50 \mathrm{mg} / \mathrm{dl}$.

\section{Discussion}

To determine the prevalence of pre-hypertension and its associated risk factors in Congolese pre and post-menopausal women was the aim of this study. To our knowledge, this is the first study that assessed pre-hypertension in a specified group of menopausal sub-Saharan African women.

Findings are depicted as follows: first, more than one third of the study population had pre-hypertension and the proportion of pre-hypertensive women was higher as compared with normotensive and hypertensive women; second, pre-hypertensive women were older than normotensive ones; third, menopause and the use of traditional medicine were the main independent risk factors associated with pre-hypertension.

The prevalence of pre-hypertension observed in our sample of menopausal women, $38.5 \%$, is close to $32.1 \%$ found in black American women aged 50 -79 years by $\mathrm{Hsia}^{25}$ in the Women Health Initiative study and in Sub-Saharan African countries. Agyemang et al ${ }^{23}$ reported a prevalence rate of $35 \%$ in Ghana and, in Ethiopia, Mengitsu ${ }^{19}$ reported a rate of $37.2 \%$; however, the population of women used in those studies were younger (from 18 years of age) than ours (40 - 60 years). This situation suggests that the prevalence of pre-hypertension in our sample of Congolese menopausal women is 
somewhat high. This prevalence is obviously lower than $43.1 \%$ found byAllal-Elasmi et al in Tunisian women aged $35-69$ years ${ }^{21}$. Inversely, Isezuo et $\mathrm{al}^{22}$ in Nigeria and Nuwaha et $\mathrm{al}^{20}$ in Uganda have reported $23.6 \%$ and $29.4 \%$, respectively.

These results are also different from ours, mainly because of the difference in age of the studied population.

In our study, twenty four percent of post-menopausal women were pre-hypertensive, which is relatively close to $27.3 \%$ found in USA for Hispanic post-menopausal wom$\mathrm{en}^{25}$. The population used in this study is ethnically different from Congolese women who took part in our study. The high prevalence of prehypertension in our sample might be attributed to the fact that menopausal women experience the change in hormonal pattern through the reduction of estrogen levels which contributes to a rise in BP through the activation of the renin-angiotensin system and the sympathetic nervous system ${ }^{26}$. In addition, the loss of estrogen can also lead to hypertension by upregulation of endothelin levels, a vasoconstrictor that augments sodium reabsorption by renal tubules ${ }^{27}$.

Pre-hypertension affects more than one third of the study population; this supports the view that, the rate of chronic non communicable diseases in developing countries is approaching the rates in the developed countries ${ }^{20}$. In the present study, compared to normotensive menopausal women, pre-hypertensive women were older. The relationship between age and the occurrence of elevated blood pressure is well documented in the literature. Indeed, the prevalence and incidence of elevated BP increase with increasing age. Data from the National Health and Nutrition Examination Survey (NHANES) showed that the prevalence of high blood pressure rose significantly with age; from $2.7 \%$ in women aged $20-34$ years to $18.4 \%$ in women aged $40-44$ years $^{28}$. On the other hand, aging is the primary risk factor for hypertension in menopausal women and it is likely to be caused in part by the falling estrogen levels during this period ${ }^{29}$.

Pre-hypertensive women were more obese than normotensive ones but the difference was borderline $(p=0.05)$. These results are different from findings in previous studies in which a significant association was found between obesity and pre-hypertension ${ }^{23}$. This difference could be attributable to the relatively small sample size. In our study, however, menopause and the use of traditional medicine were the main predictors of pre-hypertension.

The influence of menopause on blood pressure is difficult to evaluate because menopause coincides with aging $^{29}$. Some studies have reported a strong association between blood pressure and menopause. Compared to others risk factor of cardiovascular disease in women; menopause appears to be the strongest one ${ }^{28}$. In other previous studies, no such strong association between menopause and blood pressure was found ${ }^{30-32}$. The use of traditional medicine appears as another determinant of pre-hypertension in this sample of Congolese menopausal women.

In developing countries, uses of traditional medicine for primary health care may be an important risk for the development of kidney injury because of several factors: non-conventional preparations, unknown exact biological activity, unknown dosage, toxicity, interactions ${ }^{33}$. Herbal solutions are not regulated as Western medicine.

Kidneys injury caused by traditional medicine consist of different renal manifestations such as hypertension, acute tubular necrosis, acute interstitial nephritis, papillary necrosis, kidney stones, urinary retention, chronic tubule interstitial nephritis with fibrosis ${ }^{33}$. Herbal preparations can be contaminated by heavy metals and/or pesticide ${ }^{34}$. Since hypertension is a common pathway of renal disease, it is hard to distinguish whether it as a cause or a consequence. In DRC, the prevalence of hypertension increases from 10 to $28 \%$ within two decades, same for renal failure and only $8 \%$ of the population can beneft from hemodialysis because of its high cost and unavailability of the service ${ }^{35}$. Thus, managing different risk factors of hypertension is of utmost importance to prevent its adverse outcomes.

\section{Limitations}

The present study has some limitations. The cross-sectional design of our study and the small sample size limits the generalization of its findings to all Congolese menopausal women. Further studies should be conducted in order to eventually establish the relationship between the use of traditional medicine and the occurrence of pre-hypertension in Congolese women during menopause.

Another limitation is that neither the nature nor the indication of the traditional medicine was identified. Identification of those products could be helpful to prevent such adverse outcomes. 
Renal function were not assessed in this study, only proteinuria; which is quite not enough; to know exactly what is the effect of traditional medicine on the kidneys, further study should assess renal function.

The diet, one of the important factors of the occurrence of high blood pressure has not been assessed in this study; for better assessment of high blood pressure , further study should also focus in the diet.

In addition, as reported in our previous paper, menopause was defined on the basis of self-reported menstrual bleeding characteristics without hormone measurements ${ }^{17}$.

In conclusion, this study has shown that pre-hypertension is common in Congolese menopausal women. Menopause and use of traditional medicine were the main independent factors associated with pre-hypertension.

\section{Acknowledgments}

The authors would like to thank Dr Nsengi Ntamabyaliro for his advice.

\section{Conflict of interest}

The authors declare no conflict of interest.

\section{References}

1. Chobanian AV, Bakris GL, Black HR, Cushman WC, Green LA, Izzo JL et al. National High Blood Pressure Education Program Coordinating Committee, Seventh report of the Joint National Committee on Prevention, Detection, Evaluation, and Treatment of High Blood Pressure. Hypertension 2003; 42:1206-52.

2. Winegarden CR. From "prehypertension" to hypertension? Additional evidence. Ann Epidemiol 2005; 15:7205.

3. Collier SR, Landram MJ. Treatment of prehypertension: lifestyle and/or medication. Vasc Health Risk Manag 2012; 8:613-9.

4. Gu Q, Burt VL, Paulose-Ram R, Dillon CF. Gender differences in hypertension treatment, drug utilization patterns, and blood pressure control among US adults with hypertension: data from the National Health and Nutrition Examination Survey 1999-2004. Am J Hypertens 2008; 21(7):789-98.

5. Coylewright M, Reckelhoff JF, Ouyang P. Menopause and hypertension: an age-old debate. Hypertension 2008; 51(4):952-9
6. Maas AH, Frank HR. Women's health in menopause with a focus on hypertension. Nether Heart J2009; 17: 6870

7. WHO statistical information system 2007.

8. SVS Rana. Perspectives in Endocrine Toxicity of Heavy Metals-A Review. Biol Trace Elem Res 2014; 160:1-14. 9. Williams EA, Keenan KE, Ansong D, Simpson LM, Boakye I, Boaheng JM et al. The burden and correlates of hypertension in rural Ghana: a cross-sectional study. Diabetes Metab Syndr 2013; 7(3):123-8

10. Awoke A, Awoke T, Alemu S, Megabiaw B. Prevalence and associatedfactors of hypertension among adults in Gondar, Northwest Ethiopia: a community based cross-sectional study. BMC Cardiovasc Disord 2012; 28;12:113.

11. Opie LH, Seedat YK. Hypertension in sub-Saharan African populations. Circulation 2005; 112(23):3562-8.

12. Peck RN, Green E, Mtabaji J, Majinge C, Smart LR, Downs JA et al. Hypertension-related diseases as a common cause of hospital mortality in Tanzania: a 3-year prospective study. J Hypertens 2013;31(9):1806-11.

13. Arthur FK, Adu-Frimpong M, Osei-Yeboah J, Mensah FO, Owusu L. Prediction of metabolic syndrome among postmenopausal Ghanaian women using obesity and atherogenic markers. Lipids Health Dis 2012; 11:101. 14. Ogbera A, Fasanmade O, Kalra S. Menopausal symptoms and the metabolic syndrome in Nigerian women with type 2 diabetes mellitus. Climacteric 2011; 14(1):75-82. 15. Nwagha UI, Ikekpeaza EJ, Ejezie FE, Neboh EE, Maduka IC. Atherogenic index of plasma as useful predictor of cardiovascular risk among postmenopausal women in Enugu, Nigeria. Afr Health Sci 2010; 10(3):24852.

16. Arthur FK, Adu-Frimpong, Osei-Yeboah J, Mensah FO, Owusu L. The prevalence of metabolic syndrome and its predominant components among pre-and postmenopausal Ghanaian women. BMC Res Notes 2013; $6: 446$.

17. Muchanga Sifa MJ, Lepira FB, Longo AL, Sumaili EK, Makulo JR, Mbelambela EP et al. Prevalence and predictors of metabolic syndrome among Congolese pre- and postmenopausal women. Climacteric 2014;17(4):442-8.

18. Ellenga Mbolla BF, Okoko AR, Mabiala Babela JR, Ekouya Bowassa G, Gombet TR, Kimbally-kaky SG et al. Prehypertension and Hypertension among Schoolchldren in Brazaville, Congo. Int J Hyperten. 2014; 2014:803690. doi: 10.1155/2014/803690.

African Health Sciences Vol 16 Issue 4, December, 2016 
19. Mengistu MD. Pattern of blood pressure distribution and prevalence of hypertension and prehypertension among adults in Northern Ethiopia: disclosing the hidden burden. BMC Cardiovasc Disord 2014; 14:33. doi: 10.1186/1471-2261-14-33.

20. Nuwaha F, Musinguzi G. Pre-hypertension in Uganda: a cross-sectional study. BMC Cardiovasc Disord 2013; 13:101. doi: 10.1186/1471-2261-13-101.

21. Allal-Elasmi M, Feki M, Zayani Y, Hsairi M, Haj Taieb $\mathrm{S}$, Jemaa R, et al. Prehypertension among adults in Great Tunis region (Tunisia): A population-based study. Pathol Biol (Paris) 2012; 60(3):174-9.

22. Isezuo SA, Sabir AA, Ohwovorilole AE, Fasanmade OA. Prevalence, associated factors and relationship between prehypertension and hypertension: a study of two ethnic African populations in Northern Nigeria. J Hum Hypertens 2011; 25(4):224-30.

23. Agyemang C, Owusu-Dabo E. Prehypertension in the Ashanti region of Ghana, West Africa : an opportunity for early prevention of clinical hypertension. Public Health 2008; 122(1):19-24.

24. WHO Scientific Group on Research on the Menopause in the 1990s. WHO technical report series Geneva: World Health Organization 1996; 866: 1 - 106.

25. Hsia J, Margolis KL, Eaton CB, Wenger NK, Allison M, Wu L, LaCroix AZ et al.Women's Health Initiative Investigators. Prehypertension and cardiovascular disease risk in the Women's Health Initiative. Circulation 2007; 115(7):855-60.

26. Zambrana RE, López L, Dinwiddie GY, Ray RM, Phillips LS, Trevisan M et al. Prevalence and incident prehypertension and hypertension in postmenopausal Hispanic women: results from the Women's Health Initiative.
Am J Hypertens 2014; 27(3):372-81.

27. Reckelhoff JF . Cardiovascular disease, estrogen deficiency, and inflammatory cytokines. Hypertension 2006; 48(3):372-3.

28. Bateman BT, Shaw KM, Kuklina EV, Callaghan WM, Seely EW, Hernández-Díaz S. Hypertension in women of reproductive age in the United States: NHANES 19992008. PLoS One 2012; 7 (4):e36171.

29. Abramson BL, Melvin RG. Cardiovascular risk in women: focus on hypertension. Can J Cardiol 2014; 30(5):553-9.

30 .Kim HM, Park J, Ryu SY, Kim J. The Effect of Menopause on the Metabolic Syndrome Among Korean Women The Korean National Health and Nutrition Examination Survey, 2001,) . Diabetes Care 2007;30(3):701-6.

31. Gierach GL, Johnson BD, Bairey Merz CN, Kelsey SF, Bittner V, Olson MB et al. Hypertension, menopause, and coronary artery disease risk in the Women's Ischemia Syndrome Evaluation (WISE) study. J Am Coll Cardio 2006; 147: 50S-58S.

32. Rosenthal T, Oparil S. Hypertension in women. J Hum Hypertens 2000; 14:691-704.

33. Colson CR, De Broe ME. The Kidney injury from alternative medicines. Adv Chronic Kidney Dis 2005; 12; 12(3):261-75.

34. Isnard Bagnis C, Deray G, Baumelou A, Le Quintrec M, Vanherweghem JL. Herbs and the kidney. Am J Kidney Dis 2004; 44(1):1-11.

35. Sumaili EK, Krzesinski JM, Zinga CV, Cohen EP, Delanaye P, Munyanga SM et al. Prevalence of chronic kidney disease in Kinshasa: results of a pilot study from the Democratic Republic of Congo. Nephrol Dial Transplant 2009;24(1):117-22. 